\title{
Coastal and Marine Research and Capacity Building
}

Julius Francis, Louis Celliers and Sérgio Rosendo

Opposite page: Crossing hands for action, Reunion. $\odot$ Anne Lamahieu.

Most, if not all, of the recommendations contained in this State of the Coast Report, relies on two cross-cutting and fundamental qualities. Firstly, managers, decision- and policy-makers and the various end-users have access to the products of scientific research in order to wisely govern and manage the use and exploitation of resources. In this context, data, information and knowledge are the basis for realising the benefit of an Ocean Economy. Secondly, both the management of resources and the underpinning knowledge base relies on the availability of people with the appropriate capability to be responsible custodians of such resources. Accordingly, education, awareness and training offer a long-term solution for the sustainable development of a coastal and ocean economy.

The core objectives of this chapter are first, to help in the understanding of how national and regional research agendas can contribute to a consistent and complete "bigger picture" of data, information and knowledge required to manage the coastal and marine resources of the Western Indian Ocean (WIO), and secondly, present processes that contribute to the regional and national knowledgebase. The first part of the chapter will examine the past, current and future coastal and marine research priorities at various scales and how research has been or is conducted in the region. The second part of the chapter will explore the development of regional capacity for coastal and marine research and how existing research has been supported in the past. The chapter will conclude with successes on how science has contributed to decision- and policy-making in the region.

\section{NATIONAL AND REGIONAL RESEARCH}

National research and development (R\&D) activities and supporting institutional frameworks in the WIO are not homogenous. Each nation has distinctive R\&D characteristics, which are a reflection of the heterogeneity of structures and the concentration of R\&D by region, institution, sector and even project (UIS, 2010). The heterogeneity of the R\&D landscape is reflected in the supporting institutional frameworks and directly influences the coastal and marine research landscape.

Despite the differences in how countries structure their research infrastructure and priorities, Davis and Carden (1998) point out three related and common characteristics of developing countries also relevant to the WIO region. They suggest that not only is R\&D in many developing countries highly constrained by funding, but also, that resource allocation procedures are sensitive to personal or political affiliations or entitlements. This is often not balanced out by considerations of efficiency, effectiveness, relevance, utility, or excellence. Secondly, they suggest that developing countries depend on international scientific assistance, which has its own frequently changing investment agenda. Finally, Davis and Carden (1998) argue that to be effective, R\&D must be part of an "innovation system" or "innovation community", in which active relationships and communication exists between researchers 
and other actors such as intermediaries, coordinating institutions, educators, extension agents and, especially, users.

\section{Research Investment}

Socio-economic disparities between WIO states are stark, especially comparing literacy and unemployment rates. There are also large disparities in key socio-economic indicators that can influence R\&D potential such as Gross Domestic Product (GDP), which varies from US\$ 592000 million for South Africa to less than US\$ 1000 million for Comoros. According to the World Bank (The World Bank, undated) R\&D expenditure (per cent of GDP) is defined as the current and capital expenditures (both public and private) on creative work undertaken systematically to increase knowledge, including knowledge of humanity, culture, and society, and the use of knowledge for new applications. R\&D covers basic research, applied research, and experimental development. Based on this indicator, less than 1 per cent of GDP is provided to R\&D in all of the WIO countries (see Table 35.1). South Africa spends on average 0.8 per cent on R\&D (intermittently measured between 1997 and 2009) while most other WIO countries report expenditure between 0.1 and 0.4 per cent on R\&D. This does not compare favourably to developed countries which spend between 1.5 and 3 per cent of GDP on R\&D. Encouragingly, Kenya has taken a formal position on the value of $\mathrm{R} \& \mathrm{D}$ for national development by passing into law the Science, Technology and Innovation Act of 2012, which mandates a 2 per cent GDP spend on R\&D.

\section{Systems of Innovation}

Most countries in the WIO hold some level of institution- alised science, technology and innovation (STI) "system". These are primarily organised by ministries assigned to manage science and technology. In many cases, there are institutions specifically constituted to facilitate and develop STI. These innovation systems often attempt to create a relationship between national growth and development objectives, and scientific research priorities.

Over and above our understanding of the regional R\&D landscape as demonstrated by the examples in Table 35.2 , some general comments can be made relating to countries in the region:

- The extent to which the coastal and marine environment is acknowledged as an important element of national growth and development varies between countries;

- Most countries in the WIO spends less than 1 percent of GDP on R\&D activities;

- National science, technology and innovation strategies and institutional frameworks exist in some WIO countries;

- The connectedness between coastal and marine research institutions and the national STI frameworks of the WIO is often weak;

- Coastal and marine research needs are not always clearly expressed within national STI frameworks.

\section{A HISTORY OF MARINE RESEARCH AND CAPACITY BUILDING IN THE WESTERN INDIAN OCEAN}

Despite being regarded as the least studied region of the Indian Ocean, the WIO region has a long history of coastal and marine research and capacity building. Associates of Carl Linnaeus undertook the first known investigation of

Table 35.1. Research and development (R\&D) expenditure (per cent of gross domestic product) of selected countries in the Western Indian Ocean compared with India, Portugal and the United States of America.

\begin{tabular}{|c|c|c|c|c|c|c|c|c|c|c|c|c|c|c|c|c|c|}
\hline Country Name & ஃ̊ & ลू & 吕 & ू & 응 & 용 & 용 & 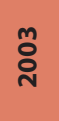 & ষ্ঠ & ڤ̊ & 응 & 융 & 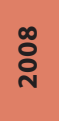 & 옹 & 응 & $\bar{i}$ & 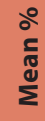 \\
\hline Kenya & & & & & & & & & & & & 0.4 & & & & & 0.4 \\
\hline Madagascar & & 0.2 & 0.1 & 0.1 & 0.1 & 0.2 & 0.2 & 0.3 & 0.2 & 0.2 & 0.2 & 0.1 & 0.1 & 0.1 & 0.1 & 0.1 & 0.2 \\
\hline Mozambique & & & & & & & 0.5 & & & & 0.5 & & 0.2 & & 0.5 & & 0.4 \\
\hline Mauritius & & 0.3 & 0.3 & 0.3 & 0.3 & 0.4 & 0.4 & 0.3 & 0.4 & 0.4 & & & & & & & 0.3 \\
\hline Portugal* & 0.6 & 0.6 & 0.6 & 0.7 & 0.7 & 0.8 & 0.7 & 0.7 & 0.7 & 0.8 & 1.0 & 1.2 & 1.5 & 1.6 & 1.6 & 1.5 & 1.0 \\
\hline Tanzania & & & & & & & & & & & & 0.4 & & & & & 0.4 \\
\hline United States* & 2.6 & 2.6 & 2.6 & 2.6 & 2.7 & 2.7 & 2.6 & 2.6 & 2.5 & 2.6 & 2.7 & 2.7 & 2.9 & 2.9 & 2.8 & 2.8 & 2.7 \\
\hline South Africa & & 0.6 & & & & 0.7 & & 0.8 & 0.8 & 0.9 & 0.9 & 0.9 & 0.9 & 0.9 & & & 0.8 \\
\hline
\end{tabular}


Recognisable Science, Technology and Innovation System

\section{Legislation and Policy}

\section{Status in relation to Coastal} and Marine Relevance
Comoros - Science and technology is primarily driven by the Ministry of National Education, Research, Culture, and Arts charged with youth and sports.
National Policy of Higher Education and Research 2020 (UDC 2013)
The focus is on strengthening the higher education and research systems which are considered extremely weak.

Does not identify research priorities in any particular area. The concept of identifying or recognising coastal land marine issues with the national system of innovation is weakly developed.
Kenya - The National Commission for Science, Technology and Innovation (NACOSTI, undated) has the goal of establishing a strong foundation on science, technology and innovation (STI), with research playing a key role in generating a critical mass of technical and skilled manpower.
Science, Technology and Innovation Act, 2013 Science, Technology and Innovation Policy and Strategy (RoK 2008).

The Kenya Marine and Fisheries Research Institute is listed as an institution to which the act applies. This institute deals with natural resources, water development, health, and power and communications. Research into the marine and coastal environment features strongly in their mandate, as does environmental and ecological management studies.

The STI policy specifically mentions the need for environmental management in order to provide a clean and safe environment for citizens while also protecting livelihoods.

Mauritius - There are a number of agencies dealing with STI ie Ministry of Industry, Science and Research, Mauritius Research Council, Rajiv Gandhi Science Centre.
Transforming Mauritius into a Knowledge Hub (HRDC 2006)
The concept of identifying or recognising coastal land marine issues with the national system of innovation is weakly developed.

The ability of the Strategy to drive coastal and marine research was difficult to assess but appears to be limited. The concept of identifying or recognising specific coastal land marine issues within the national system of STI is weakly developed. It does not appear to facilitate a process for the expression of national research priorities, and the engagement of research with national research funding instruments appears to be limited.

South Africa - The Department of Science and Technology (DST) is responsible for scientific research in the country and oversees the management of the country's relatively well-developed science system. The key institution, in the context of this strategy, for promoting science, is the National Research Foundation, which is linked to the higher education sector through the National Plan for Higher Education
Mozambique Strategy for Science, Technology and Innovation (RoMZ 2006)
The strategy document does not make any special mention of the biophysical environment or the coastal/ marine environment. The concept of identifying or recognising coastal land marine issues with the national system of innovation is moderately developed.
Tanzania - The Commission for Science and Technology (COSTECH) is a semi-state organization with the responsibility of co-ordinating and promoting research and technology development activities in the country (COSTECH, undated). It is the chief advisor to the Government on all matters pertaining to science and technology and their application to the socio-economic development of the country. Major national research and development institutes are affiliated to COSTECH.
National Research and Development Strategy (RSA 2002)
It's quite difficult to discern the relevance of this organisation to coastal and marine environment issues in Tanzania. Very few of the R\&D institutions listed on their website deal specifically with the coastal environment (Tanzania Fisheries Research Institute for example) while the majority of them are focused on agriculture and livestock, industry and energy, and medicine and public health. marine life in the WIO region in the mid-1700s (Richmond 2011). Further investigations followed years later and were undertaken as part of major global exploratory expeditions. These include expeditions such as H.M.S. Endeavour (1768-71), H.M.S. Beagle (1831-1935) and Challenger (1873-76) (Richmond 2011). Since then, scientific cruises and expeditions have continued to be an important means for conducting scientific research, particularly in offshore areas. Importantly, most of the cruises in the region were conducted by foreign countries such as Belgium, Norway, Germany, the Netherlands and United Kingdom. South Africa is the only country in the region that has organized regional cruises. In the other countries, locally organized cruises have concentrated on waters within national bor- 
ders. Accordingly, most of the marine research conducted in the region to date has encompassed nearshore waters using small vessels that are limited in range and technical capacity. One outcome of this situation is that there is some reasonable understanding of a few of the key habitats and ecosystems close to shore, but the regional knowledge of deep-water habitats and resources is rather limited.

By the early 1960s, only five research institutions/stations existed in the WIO region. These were: the Maritime and Fisheries School of Mogadishu; the East African Marine Fisheries Research Organization (EAMFRO), with substations in Mombasa and Zanzibar; the Institut de Recherche Scientifique (Madagascar); the Inhaca Island Marine Biological Station (Mozambique) and the Oceanographic Research Institute (ORI) (South Africa). Their main focus was to compile inventories of marine life and resources, particularly fisheries. The situation is different today, as the number of academic and research institutions that deal with different aspects of marine science has increased significantly, with all the WIO countries having more than one institution (Table 35.3).

Most of the research institutes in the region have basic field instruments, boats, diving gear, and specialized laboratories, with infrastructure and laboratories in most cases developed intermittently through externally funded projects. Various capacity-building activities have been undertaken within and outside the region under the auspices of a range of donor organisations. Examples include support from the governments of Sweden (through Sida and SAREC), Norway (through NORAD), Japan (through JICA), and overseas development assistance (ODA) facilities offered by many other governments, as well as structured partnerships between local and foreign universities (historic), and China and South Korea, more recently. Within these initiatives, short-courses and training workshops (1-3 weeks), with some longer-term degree courses (1-4 years) has been a primary vehicle for improving local capacity.

The relationship between science and policy in the region has changed considerably over the years. Traditionally the pipeline mode existed in which scientists set the research agenda, conduct the research, and then transfer the results to potential users. This has evolved into co-production of knowledge under a more modern approach, whereby scientists and decision-makers define the research agenda and on a regular basis scientists provide feedback to the policy community. Whilst the full gains from this transition have not yet been totally appraised or audited (accounted) for, the extent to which this new approach has improved awareness and engagement in marine resource management is reflected by the investments being made in this domain. This change has been possible due to the associated change occurring in the way in which research topics are selected. Historically, research topics were commonly selected to meet academic criteria and most of the times reflected the interests of either students or supervisors with limited or no links to priority resource management questions. In the recent past, and through programmes such as Marine Science for Management (MASMA), through WIOMSA, inter and multi-disciplinary research has been promoted to address urgent societal and resource management issues.

\section{Pre-independence}

Prior to the 1960s most countries in the WIO region were under colonial rule. Accordingly, marine and coastal research in these countries was driven by the perspectives of remote decision-makers who relied on reports rather than direct local engagement. Importantly, however, a number of developments which took place during this period are the foundation for some of the institutional capacity currently existing in the region.

The notable pre-independence scientific cruises and expeditions that took place from 1789 to 1960 (described above), were followed by the 20th century expeditions of H.M.S. Mabahiss (1933-34) and the International Indian Ocean Expedition (IIOE) (1959-1965). The IIOE involved scientists from 23 countries, 44 research vessels and numerous airborne data-collecting devices and satellites (Morcos 2002). Whilst early expeditions focused mainly on the collection of biological specimens and plankton, the study of biological and chemical processes, inventories of marine life and resources, particularly fisheries, and recording of basic oceanographic processes, the later IIOE encompassed almost all marine science disciplines, except perhaps fishery research and marine microbiology (Rao and Griffiths 1998). The IIOE contributed a wealth of knowledge on many aspects of the WIO including the discovery of the mid-Indian Ocean ridges (including the Southeast Indian Ocean Ridge) the famous triple junction south of the Seychelles, where the southern end of the Carlsberg Ridge meets the Southwest Indian Ocean Ridge (Rao and Griffiths 1998), the effects of the monsoons on the Somali Current, and upwelling off the Somalia coast. 
In addition to oceanic expeditions, this period was also characterised by the establishment of the first initiatives leading to the founding of marine biological stations. These were:

- The founding of the Zanzibar Marine Station in 1948 with the Mombasa Marine Station and the ensuing formation of the East African Marine Fisheries Research Organization (EAMFRO), in 1953. The Zanzibar Marine Station has become the Institute of Marine Science (IMS) of the University of Dar es Salaam and the Mombasa Marine Station is now the Kenya Marine Fisheries Research Institute (KMFRI).

- The Inhaca Island Marine Biological Station, established by the Portuguese administration in 1953 in conjunction with the University of the Witwatersrand, is now part of the Universidade Eduardo Mondlane (UEM).

- Between 1962 and1973, the French organization 'Office de la Recherche Scientifique et Technique d'OutreMer' (OSTROM) established and managed a marine station in Nosy-Be, Madagascar, later reopened in 1978 as the Centre National de Recherches Oceanographiques (CNRO).

- In 1961, the University of Marseille established 'Station Marine de Tulear', attached to the Faculty of Science, University of Antananarivo. This station became L'Institut Halieutique et des Sciences Marines de l'Universite de Tuléar.

- The Oceanographic Research Institute (ORI) was established as the research wing of the South African Association for Marine Biological Research, a non-profit NGO affiliated to the University of Natal, in 1953/4.

Despite the existence of these stations during the IIOE, their limited human resources and technical capacity largely prevented them from participating in the expedition or benefitting directly from training and educational opportunities provided by the International Oceanographic Commission (IOC) of the United Nations Educational, Scientific and Cultural Organization (UNESCO).

In addition, there were no universities or colleges in the region offering courses in marine sciences during this period, such that apart from ORI, all of the scientists working in these research stations were foreigners.

\section{Post-independence to the 1980s}

Most of the countries in the WIO region achieved independence between 1961 and 1976. As governments across the region strived to consolidate their economies and infra- structure in the early 1960 's, marine science research was not given priority. For instance, in 1962, a decision was taken to close the EAMFRO as it was argued that marine science was unlikely to provide immediate economic benefit to East Africa. This decision was later rescinded (EAMFRO 1965).

From the 1970s onwards, a change in thinking began to emerge, resulting in the implementation of a range of initiatives that played a catalytic role in the development of marine science in the region, including capacity-building programmes. In April 1974, the International Centre for Marine Resources Development of the University of Rhode Island organized the International Conference on Marine Resource Development in East Africa in collaboration with the University of Dar es Salaam. This conference was specifically aimed at providing a discussion forum for scientific and developmental issues pertaining to marine science capabilities in the region. It also encompassed issues related to the marine resource potential and capacity needs of the East Africa region. Notably, the conference recommended the establishment of an institute of marine sciences at the University of Dar es Salaam (Morcos 2002). Three years later, with the collapse of the East African Community (EAC) and EAMFRO, the University of Dar es Salaam took over the facilities in Zanzibar and established the Institute of Marine Sciences in 1978.

Another important event that played a key role in the development of scientific research in the region was the creation of a regional body, the Cooperative Investigations in the North and Central Western Indian Ocean (IOGINCWIO), by the IOC of UNESCO. Two preparatory meetings were held to prepare for the establishment of the IOCINCWIO, the first in Zanzibar in 1975, and the second in Nairobi the following year. Several oceanographic and atmospheric research programmes were undertaken in the region between these meetings and the first session of the IOCINCWIO was convened in 1982. The initial research programmes included the Special Observing Period Program of the Monsoon Experiment (MONEX) which took place in 1978 to 1979 and carried out oceanographic and atmospheric observations on the whole of the Indian Ocean north of $10^{\circ} \mathrm{S}$. In the WIO region, the studies focused on phenomena such as the Equatorial Current, Somali Current and upwelling currents off Somalia (Morcos 2002).

Throughout the 1970s governments in the region increasingly recognised the importance of marine science and awareness of coastal and marine issues grew widely. 
This was significant in influencing the Third UN Conference on the Law of the Sea, which started in 1973, and culminated with the adoption of the UN Convention for the Law of the Sea in 1982. The latter resulted in the establishment of the United Nations Environment Programme (UNEP) in 1973 and subsequently a Regional Seas Programme by UNEP that also helped to enhance technical support on marine research from UN organizations and developed countries. Between 1970 and 1980, technical assistance and financial support for national and regional marine science projects came from UN organizations such as the IOC, UNESCO, FAO, and World Meteorological Organization (WMO). Developed countries, such as the US, Norway, UK, Canada and France provided technical assistance and opportunities for undergraduate and postgraduate training through bilateral programmes. The Norwegian Government provided the R/V Fridtjof Nansen to the Mozambique Government, and later to other governments, to conduct fisheries and oceanographic surveys in Mozambican waters in 1977-1978.

The 1970s were also marked by missions to the region by developed countries on their own initiative or in collaboration with the UN organizations. These commonly aimed to investigate the priorities and needs for capacitybuilding in the marine sciences and included visits to Kenya, Madagascar, Somalia and Tanzania.

\section{From the 1980 s to the present}

As a reflection of the importance of marine and coastal resources, the past 35 years has seen a remarkable growth in marine science research across countries in the WIO region. This is exhibited by both the enhancement of existing programs and the development of new initiatives. This has encompassed regional legal and institutional frameworks, academic and research institutions, regional research programmes, increased financial and technical support, and increased partnerships.

\section{New and Existing Regional research and management Frameworks for marine and coastal environment}

A number of collaborative activities between funding agencies, donors and regional governments were implemented between 1997 and 2001. Notably, the IOCINCWIO, funded by IOC, Sida, the Belgian Government and UNEP implemented a number of activities. These included providing funds for regional cooperation in scien- tific information exchange, ocean mapping, a regional nutrient and water quality monitoring network, the installation and maintenance of sea level stations and strengthening regional institutions such as WIOMSA. Activities on scientific information exchange were built on the foundation laid by the Belgium Government-supported project 'Regional Cooperation in Scientific Information Exchange in the Western Indian Ocean region' (RECOSCIX-WIO), which was established in 1989 and focused on the development of capacity and infrastructure for the collection, processing, archiving, analysis, interpretation and dissemination of data and information. The RECOSCIX-WIO project ended in 1997 and was replaced by the Ocean Data and Information Network for Africa (ODINAFRICA), which started in 1997 and is now in its fourth phase. The focus of the current phase of the project is on product development and dissemination and strengthening of the Pan African network of National Oceanographic Data Centre (NODCs). The project has produced directories, catalogues, atlases and portals.

With more of a focus on management and coastal protected areas, the Convention for the Protection, Management and Development of the Marine and Coastal Environment of the Eastern Africa Region (Nairobi Convention) was enacted in 1985 and came into force in 1996 through its East Africa Action Plan. This initiative supported the implementation of a number of projects focusing on management and protection of coastal areas (EAF/5), the control of marine pollution (EAF/6) and a regional database and atlas of coastal and marine resources (EAF/14). In contrast to the historic situation in the 1970 s and 1980s, the projects in this program were implemented by research and academic institutions in the Convention countries rather than by external research organisations or institutions.

In 2004, the Nairobi Convention facilitated the establishment of the Forum of Heads of Academic/Research Institutions (FARI). Core objectives of the Forum were to facilitate the sharing of information between these institutions and the Nairobi Convention, as well as amongst themselves; engage and facilitate opportunities for collaborative research that are relevant to the Nairobi Convention; and offer scientific and technical advice on priorities for management, assessments and information dissemination within the Nairobi Convention.

The Nairobi Convention Secretariat was the Executing Agency for the GEF-funded project "Addressing landbased Activities in the Western Indian Ocean," (WIO-LaB 
Project), which undertook a region-wide assessment of transboundary problems and issues affecting the marine environment in the WIO region between 2004 and 2010. The outputs of these assessments led to the formulation of a Transboundary Diagnostic Analysis (TDA), detailing key problems and causes of degradation of the coastal and marine environment in the WIO region, with special emphasis on land-based sources and activities (LBSA) and the Strategic Action Programme (SAP) to address the challenges faced by governments in the region.

Both IOCINCWIO and the Nairobi Convention leveraged national support by involving research and academic institutions in the region in the implementation of their activities and, thereby, contributed to strengthening national institutional and human capacity.

\section{New and Existing Legal and Institutional Frameworks}

Both the 1992 UN Conference on Environment and Development in Rio de Janeiro, and the 2002 World Summit for Sustainable Development in Johannesburg, prompted many countries, including the WIO countries, to revise or develop national legal instruments, on environment, by incorporating principles of sustainable development. For instance, Tanzania developed the following environmental-related policies and acts after these major conferences: the Marine Parks and Reserves Act (1995), the National Environment Policy (1997), the National Fisheries Sector Policy (1997) and the National Integrated Coastal Management Strategy (2003). Similar action was taken by the other WIO countries.

Research and academic institutions were involved in the revision and development of new legal instruments, and further provided technical inputs to the processes and benefitted from the policy-making community thereby strengthening the relationship between science and policy making. Research and academic institutions have contributed to the implementation of some of the aspects of the legal instruments. In Tanzania, research and academic institutions were actively involved in the drafting of the Marine Parks and Reserves Act and the National Integrated Coastal Management Strategy and their implementation. As an example of the latter, the Institute of Marine Sciences played an important role in the establishment of the Mafia Island Marine Park and Mnazi Bay Marine Park between 1995-2000 as part of the implementation of the Marine Parks and Reserves Act.

\section{New and Existing Academic and Research Institutions}

The increase in human capacity for marine science research, as well as increasing recognition of the importance of the marine ecosystem goods and services by governments has led to the establishment of new academic and research institutions (Table 35.3). More universities in the region are now offering postgraduate degree programmes in areas of marine and coastal science and associated resource management disciplines. For instance, in Kenya, the number of universities that teach courses with a marine and coastal focus has increased from one before 1980 (ie University of Nairobi) to more than five. In the 1980s, the University of Dar es Salaam offered courses on marine systems in the Department of the Zoology and Marine Biology but this was changed first to the Faculty of Aquatic Sciences and Technology and later to the Department of Aquatic Sciences and Fisheries, which currently offers two degrees programmes at the undergraduate level. Both the Department of Aquatic Sciences and Fisheries and the Institute of Marine Sciences now offer Masters and PhD degree programmes. In Mauritius, both the Albion Fisheries Research Institute and the Mauritius Oceanography Institute were established after 1980.

At present, there is at least one University offering degree programmes on marine related field in all the countries in the region except Somalia. Additionally, a number of non-governmental organizations have increased their support to research by publishing seminal papers to complement the traditional academic and research institutions. The Wildlife Conservation Society, through its Kenya and Madagascar offices, and CORDIO have been the most active.

\section{Development of Bilateral and Regional Research Programmes}

Since the 1980s the region has benefited from a number of bilateral and regional research programmes which have contributed significantly to strengthening of human and institutional capacity in regional academic and research institutions. Perhaps just as importantly, these programmes have also underpinned the development of strong partnerships between regional institutions and their counterparts in developed countries. Examples of such programmes include the following:

- The Sida/SAREC Regional Marine Science Programme started in 1993 with the aim to carry out 
research on the sustainable use of coastal and marine resources, and environmental management of the coastal zone. This Programme supported the two Ministerial Conferences on Integrated Coastal Zone Management (ICZM) in Arusha, Tanzania (1993), and the Seychelles (1996). These events set the stage for coastal management initiatives at local and national levels in the region and successfully initiated dialogue between the scientific community and high-level policy-makers. The programme made modest investments in capacity building in the social sciences, which resulted in notable achievements in this arena. This Programme also facilitated the establishment of WIOMSA and CORDIO.

- The Sida/SAREC Marine Science Bilateral Programme for Tanzania and Mozambique. The Bilateral Program for Mozambique was initiated in 1985 while the Bilateral Program for Tanzania started in 1990. Both programmes are still ongoing. Their combined impact has produced significant advances towards the goal of a diversified resident capacity in the marine sciences that will contribute towards effective management of coastal ecosystems. This has, in turn, prompted greater local investments in the natural sciences to increase this diversity and the wider local capability in coastal resource management disciplines. The programme's most notable achievement has been the transformation of the Institute of Marine Sciences (IMS) of the University of Dar es Salaam into an internationally recognized institution. IMS is attracting funds from a diversity of sources, hosts visiting scholars from many nations, and is making significant contributions to public policy and resource management in Zanzibar, Tanzania and the region.

- The Kenya - Belgium Programme in Marine Sciences. This programme started in 1985 and involved the Free University of Brussels (VUB) and the KMFRI, resulting in the training of a number of Kenyan students to Masters and PhD level. The programme also supported a number of studies in Kenya undertaken by Kenyan and Belgium scientists. It also constructed and equipped laboratories at KMFRI.

- GEF-funded regional programmes. The region implemented three regional GEF-funded projects during the ten years from 2004 to 2014. These were Addressing Land-Based Activities in the Western Indian Ocean' (WIO$\mathrm{LaB})$, 'the Southwest Indian Ocean Fisheries Project' (SWIOFP) and the Agulhas and Somali Current Large Marine Ecosystems Project' (ASCLME). Scientists and experts from regional universities and research institutions, as well as government agencies, were closely involved in project activities including through participation in regional and national task forces and working groups, preparation of the TDA and SAP and in advisory roles to the demonstration projects. The project collaborated closely with WIOMSA and facilitated creation of the Forum of Heads of Academic and Research Institutions (FARI) in the region as a mechanism to coordinate research activities and assure the quality of scientific work in the region. The ASCLME and SWIOFP Projects, together with partners in the EAF Nansen Project, NOAA, NIOZ, IUGN and the IRD, undertook or co-funded over 50 offshore expeditions in the WIO region (Box 35.1).

- EU-funded projects. From the mid-1990s up to 2010, the European Union supported a number of research programmes in the region through its framework programme: Specific Measures in Support of International Cooperation (INCO-DEV). These included the 'Transboundary networks of marine protected areas for integrated conservation and sustainable development: biophysical, socio-economic and governance assessment in East Africa ('TRANSMAP)' and the 'Peri-urban mangrove forests as filters and potential phytoremediators of domestic sewage in East Africa (PUMPSEA)'. A total of 24 research and management authorities in regional participating countries and European institutions were involved in these projects. They supported a number of Masters and PhD candidates, undergraduate students, provided equipment, and produced a number of high quality publications and scientifically based advisory documents for application in policy development and management.

- Marine Science for Management (MASMA). In 2001, WIOMSA initiated a regional programme known as Marine Science for Management (MASMA) with financial support from Sida/SAREC. A principal component of MASMA is a competitive grants programme to support regional research. In addition to this, there are three other related and mutually reinforcing operational components of MASMA: 1) Institutional strengthening of WIOMSA to administer and coordinate research activities; 2) training and outreach in the region, regional networking, research priority setting and professional development through short courses, seminars, and workshops; and 3) the communication and dissemination of research results and information. WIOMSA has organized eight Scientific Symposia through this programme, which have been held triennially since 1997, it has established the Western Indian Ocean 
Journal of Marine Science in 2002, produced 16 books under its Book Series, and supported other books published by prominent publishing firms such the Oxford University Press and University of Cape Town Press. Between 2000 and 2014, WIOMSA supported at least 210 Marine Research Grant (MARG-I) projects and 46 large regional research projects, which were implemented in all the countries in the region except Somalia. Over 600 publications have been produced through these grants (Figure 35.1).

\section{Increased financial and technical support}

In most of the countries in the region budgetary allocations for research and capacity-building by governments are generally insufficient and highly variable. Government funds are almost exclusively sed to pay for salaries alone. This funding limitations means that most of the research and capacity-building initiatives in the region have been, or are funded by bilateral and multilateral funding agencies, international NGOs and foundations.

As indicated previously, marine sciences and capacitybuilding initiatives in the WIO region have historically received significant levels of support from these external sources. This support has been directed towards research projects, the provision of scholarships for postgraduate training, organisation of workshops and courses, and, in some cases, the provision of physical infrastructure (including laboratories, libraries and lecture rooms) and supplies. To illustrate the increasing levels of support received in the WIO through WIOMSA, the Government of Sweden financial support to WIOMSA from its establishment in 1995 to 2011 is used as an example (Figure 35.2).

\section{Increased Partnerships}

Different types of partnerships have been developed through bilateral and regional programmes, including south-north and south-south partnerships. These partnerships have resulted in enhanced collaboration in research and capacity-building amongst experts, both within the region and between the region and outside. Successes of these partnerships are reflected in the increased number of joint proposals developed and implemented, an exchange of students and staff, and the joint production of publications.

The Sida/SAREC Regional Marine Science Programme, Sida/SAREC Marine Science Bilateral Programmefor'Tanzania and Mozambique, the Kenya-Belgium Programme in Marine Sciences, EU-funded programmes under the Framework programme and MASMA, have all contributed to strengthen the collaboration between research and academic institutions in the WIO and those in Europe (such as the Stockholm University in Sweden, University of Lisbon, Free University of Brussels), Australia (the University of Queensland and James Cook University) and USA (University of Rhode Island).

Partnerships between and among institutions in the region have also improved over the last decade. This improvement is also largely attributable to the bilateral and regional programmes that have catalysed exchange, inter-

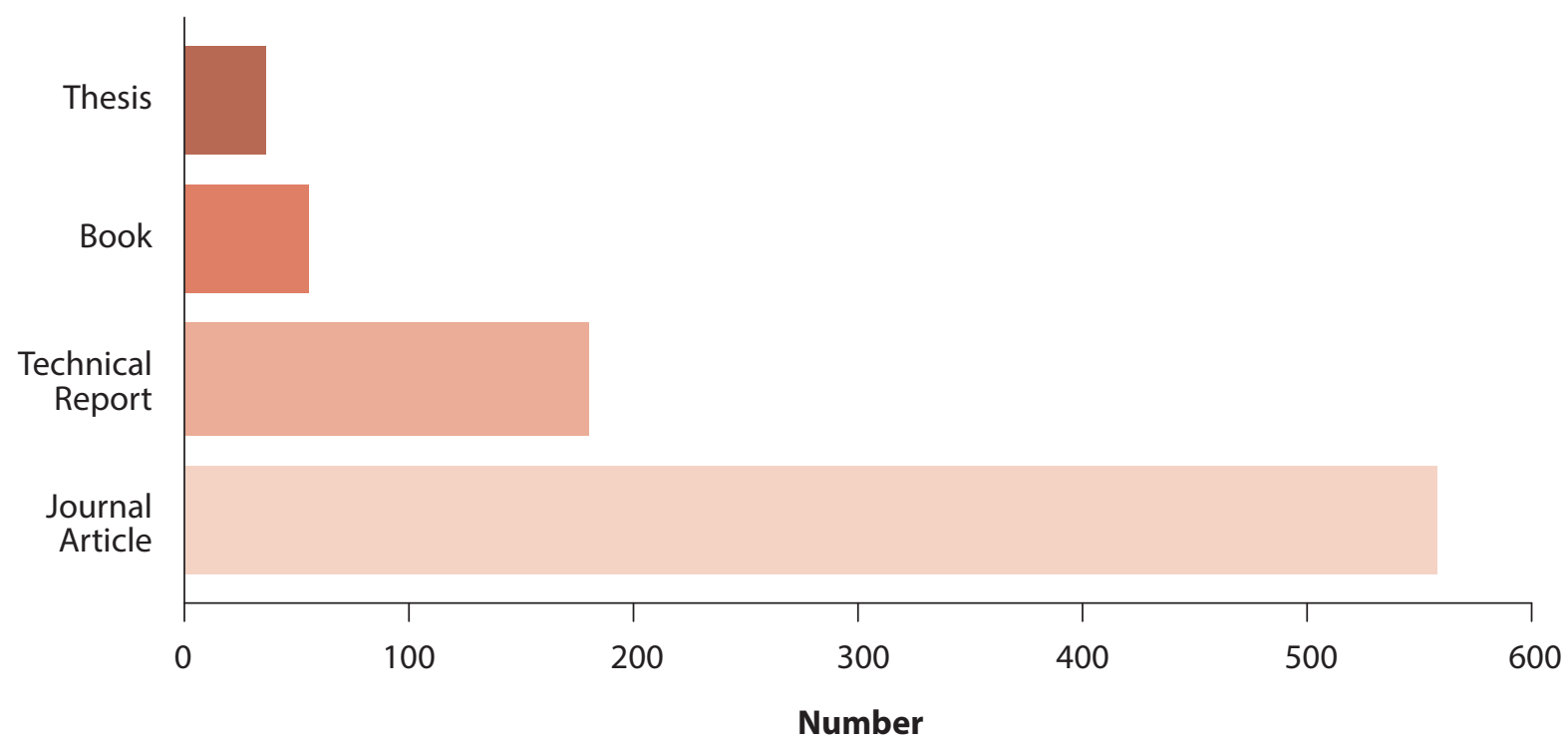

Figure 35.1. Publications produced with support of WIOMSA between 2000 and 2014. Source: data from Google Scholar. 


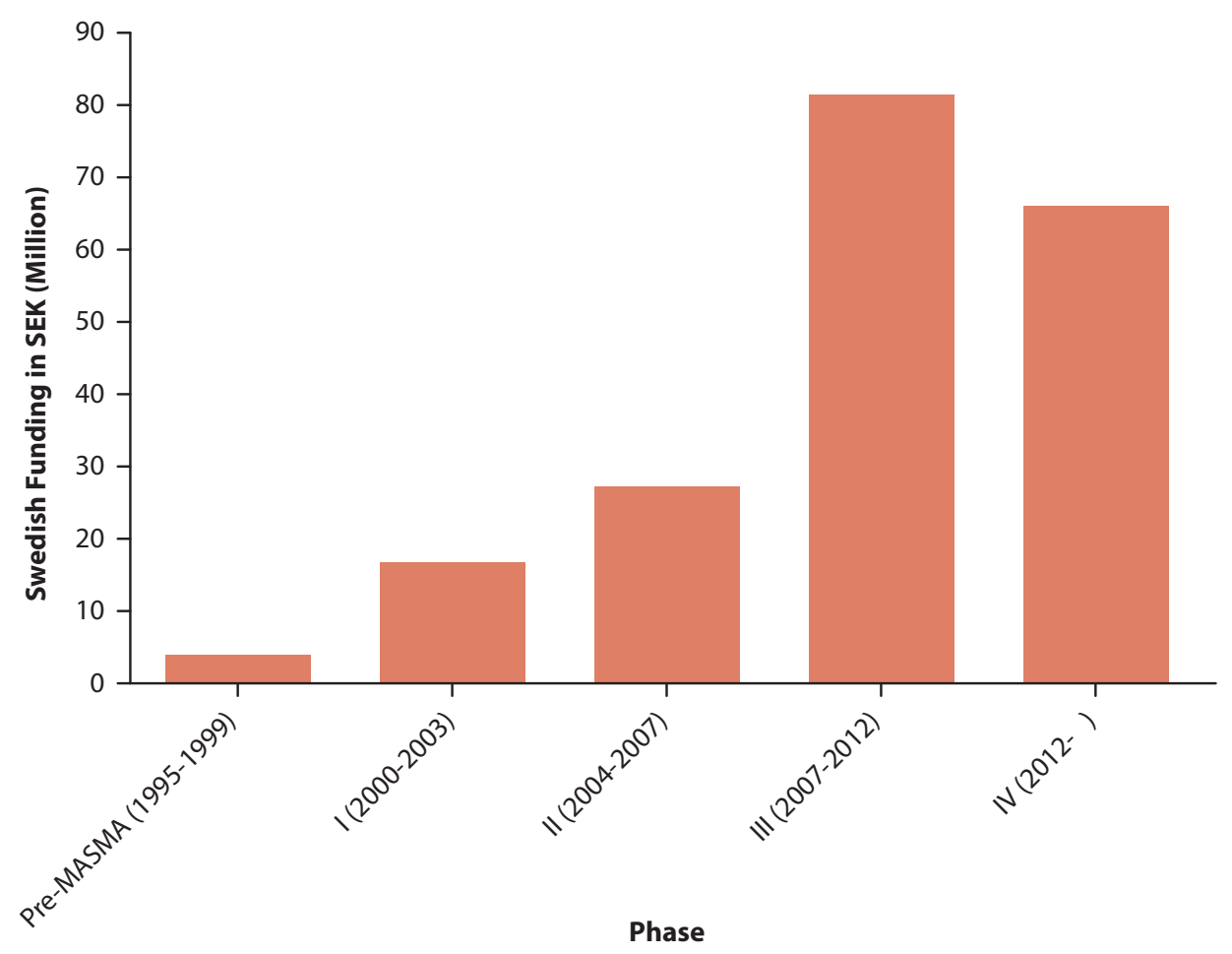

Figure 35.2. Government of Sweden support to WIOMSA from 1995 to 2015.

action and dialogue between organisations such that new relationships have been supported to become strong longstanding partnerships (eg KMFRI-IMS, ORI-UEM). MASMA has also played a key role in strengthening southsouth partnerships by having this prerequisite as one of its main requirements to secure funding. Partnerships between academic and research institutions in Kenya and Tanzania, Tanzania and Mozambique, Mozambique and South Africa and South Africa with Mauritius and Reunion have been established through MASMA and EU-funded projects, a number of which are on-going.

\section{WHO IS CONDUCTING RESEARCH?}

In the WIO, government research institutions are important actors in the production of knowledge relevant to the coastal and marine environment. This is particularly the case in fisheries, but some countries also have research institutions concerned with a variety of coastal and marine environment domains. In some government-affiliated research institutions, and in particular kinds of research, there is a direct linkage between the production of knowledge and its application. Management authorities in the region often meet their knowledge needs by commissioning studies to government research institutions, consult- ants and, sometimes, universities (Figure 35.3). In this case, there is also a direct link between research and its application. However, there are also a number of institutions producing unsolicited research that could contribute to coastal and marine management but there are no formal mechanisms that could be used to channel them through.

\section{RESEARCH UPTAKE}

The use of research outputs by decision- and policy-makers cannot be represented as a linear relationship between supply and demand. How and why science is produced and balanced between national and local needs is influenced by, amongst other things, the availability of funds which may or may not be linked to national and sub-national (provincial, district, local) priorities. Given the significant percentage of the research budget that comes into the WIO from external sources, and not national budgets, research agendas may sometimes not be well harmonised with national or sub-national needs. In the WIO, lack of clearly expressed national research priorities for marine and coastal management is an important factor that limits the potential to improve this alignment need and, accordingly, the applicability of research for management, decision and policy 


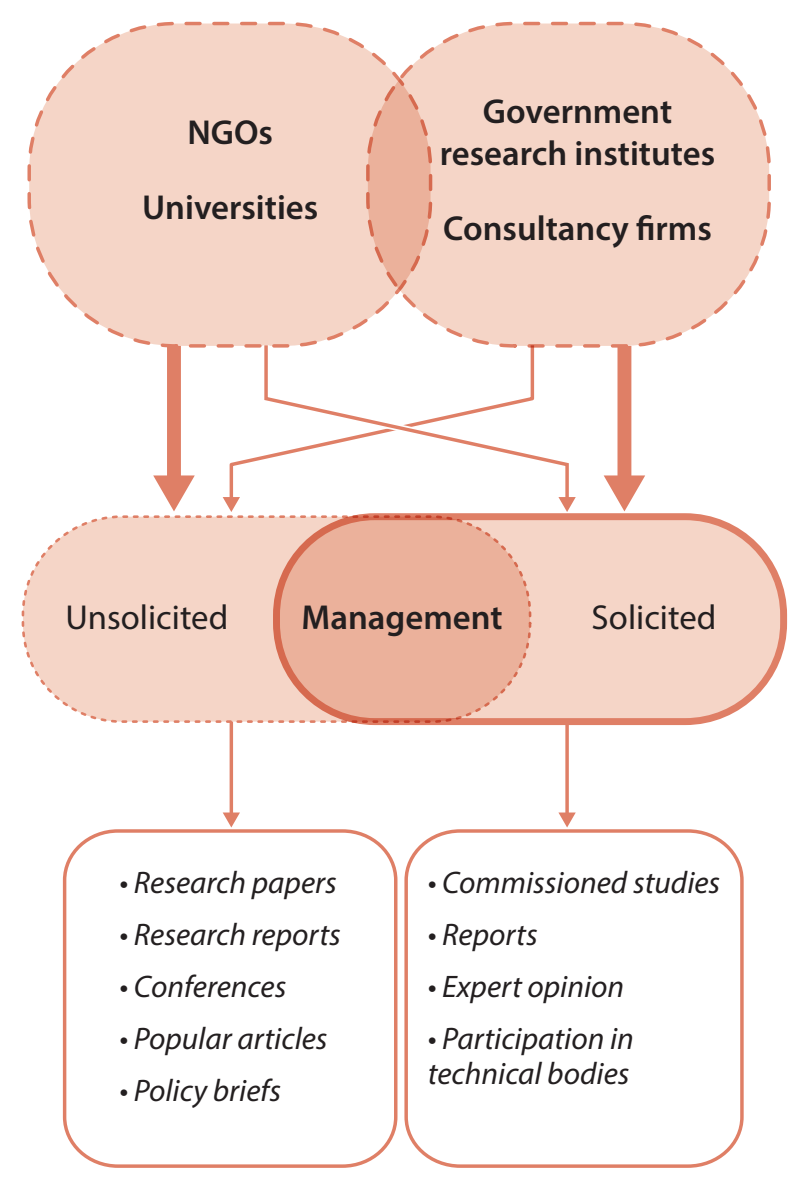

Table 35.3. Research and academic institutions in the WIO region (those with degree programmes in marine sciences are bulleted).

purposes.

The mechanisms used by research institutions to couple science to management, and barriers to achieve this, are contextual and vary between countries. Research institutions in the region are generally committed to producing research that contributes to national development needs, including those related to the sustainable management of the coastal and marine environment. Similarly, scientists in both government-affiliated and academic institutions recognise the importance of undertaking applied research and transmitting research results to potential users. Despite wide acceptance of the need to link science and management, the mechanisms to identify research priorities in the coastal and marine environment and to communicate research results to managers and policy-makers are often still poorly developed.

It is also clear that simply transmitting scientific results to decision-makers, while important, is not sufficient to effectively enable their uptake by managers. The use of science by decision-makers in the region, and elsewhere in the world, is influenced by many procedural, technical, and political factors. The role of individual and institutional values is also important. In this context, there continues to be a need for the development of new and innovative approaches to better integrating research agendas with management planning and decision-making processes such that both the development of research and the products it delivers are better integrated into an overall approach to natural resource management.

Examples of science that supports management can be gleaned from cases involving institutions and procedures that explicitly connect science to management. These can take many forms, but often involve mechanisms to identify and fund emerging research. Studies linked to extension or that include a demonstration of the feasibility of new approaches and solutions, and are ultimately aimed at replication, appear to be more successful in their 'uptake'. For instance, the MASMA-funded project, "Determination of the Distribution and Characteristics of Fish Spawning Aggregation Sites (FSAS) and their Importance to the Artisanal Fisheries Resources of Seychelles", successfully convinced the Islands Development Company (IDC) of Seychelles (that was 
Figure 35.3. Reported flow of communication between institutions producing science and agencies that use science related to research, development and management of the coastal and marine domain of the Western Indian Ocean states.

\begin{tabular}{|c|c|c|}
\hline Country & Government research institutions and Universities & $\begin{array}{l}\text { Non-governmental } \\
\text { organizations }\end{array}$ \\
\hline Comoros & University of the Comoros & \\
\hline Kenya & $\begin{array}{l}\text { Kenya Marine and Fisheries Research Institute (KMFRI) } \\
\text { Technical University of Mombasa } \\
\text { BSc (Marine Resource Management \& Fisheries and Oceanography) } \\
\text { MSc (Fisheries and Aquaculture) } \\
\text { Eldoret University } \\
\text { BSc (Coastal and Marin e Resource Management) } \\
\text { South Eastern Kenya University } \\
\text { BSc ( Fisheries Management and Aquaculture Technology; Aquatic Sciences) } \\
\text { MSC Aquaculture } \\
\text { Pwani University } \\
\text { BSc (Marine Biology and Fisheries) } \\
\text { PhD (Fisheries) } \\
\text { Jomo Kenyatta University of Agriculture \& Technology (JKUAT) } \\
\text { BSC (Fisheries and Aquaculture Sciences and Marine Engineering) } \\
\text { MSC (Aquatic Ecology and Fisheries and Phycology) }\end{array}$ & \\
\hline Madagascar & $\begin{array}{l}\text { Institut Halieutique et des Sciences Marines (IHSM), University of Tuléar } \\
\text { BSc, MSc and PhD } \\
\text { Centre National de Recherche Oceanographic (CNRO) } \\
\text { Station de Recherche Oceanographique de Vangaindrano (SROV) }\end{array}$ & Blue Ventures, CETAMADA \\
\hline Mauritius & $\begin{array}{l}\text { University of Mauritius } \\
\text { BSc (Marine Science and Technology) } \\
\text { MSC and PhD } \\
\text { Albion Fisheries Research Institute } \\
\text { Mauritius Oceanography Institute }\end{array}$ & Marine Conservation Society \\
\hline Mozambique & $\begin{array}{l}\text { University of Eduardo Mondlane } \\
\text { BSc (Marine, Aquatic and Coastal Biology; Oceanography; Marine Chemistry; Marine } \\
\text { Biology; Environmental Engineering; Fisheries Production) } \\
\text { MSc (Sustainable Aquaculture; Applied Oceanography; Marine Biology and } \\
\text { Fisheries Management; Coastal and Environmental Geology; Environmental } \\
\text { Engineering; Aquatic Biology and Coastal Ecosystems) } \\
\text { Nautical College of Mozambique } \\
\text { BSc (Marine Engineering; Law of the Sea; Maritime Shipping) } \\
\text { Polytechnic Institute of Gaza } \\
\text { BSC (Fish Farming) } \\
\text { National Institute for Hydrograph and Navigation (INAHINA) } \\
\text { National Fisheries Research Institute (IIP) } \\
\text { Centre for Research of Marine and Costal Environment (CEPAM) }\end{array}$ & $\begin{array}{l}\text { CTV } \\
\text { Ocean Revolution }\end{array}$ \\
\hline Reunion & $\begin{array}{l}\text { University of Reunion } \\
\text { MSC (Biodiversity, Ecology \& Evolution) } \\
\text { IFREMER } \\
\text { IRD }\end{array}$ & $\begin{array}{l}\text { ARVAM } \\
\text { Globice } \\
\text { ARDA } \\
\text { CapRun } \\
\text { CRPMEM } \\
\text { BIOTOPE } \\
\text { Ocea-Consult } \\
\text { BRGM } \\
\text { Pareto } \\
\text { Vie Oceane } \\
\text { Ocea Consult }\end{array}$ \\
\hline Seychelles & $\begin{array}{l}\text { University of Seychelles } \\
\text { BSc in Environmental Science } \\
\text { Seychelles Fishing Authority }\end{array}$ & Nature Seychelles \\
\hline South Africa & $\begin{array}{l}\text { Council for Scientific and Industrial Research } \\
\text { University of KwaZulu-Natal } \\
\text { University of Cape Town } \\
\text { Nelson Mandela Metropolitan University }\end{array}$ & $\begin{array}{l}\text { Oceanographic Research } \\
\text { Institute }\end{array}$ \\
\hline
\end{tabular}




\begin{tabular}{|c|c|c|}
\hline Country & Government research institutions and Universities & $\begin{array}{l}\text { Non-governmental } \\
\text { organizations }\end{array}$ \\
\hline Tanzania & $\begin{array}{l}\text { University of Dar es Salaam } \\
\text { Department of Aquatic Sciences and Fisheries (Aquatic Environmental Sciences } \\
\text { and Conservation and Fisheries and Aquaculture and MSc in Fisheries and Aquacul- } \\
\text { ture and PhD ) } \\
\text { Institute of Marine Sciences (MSc in Marine Science and PhD) } \\
\text { Tanzania Fisheries Research Institute (TAFIRI) }\end{array}$ & Sea Sense \\
\hline Regional NGOs & $\begin{array}{l}\text { Wildlife Conservation Society } \\
\text { CORDIO } \\
\text { WWF } \\
\text { CI } \\
\text { IUCN } \\
\text { WIOMSA }\end{array}$ & \\
\hline
\end{tabular}

involved in the fishing of grouper spawning aggregations) to agree to stop the practise after being presented with the project's results (Robinson and others, 2007).

Finally, projects that involve high degrees of collaboration between scientists, managers and resource users at all stages of the work are more likely to result in outputs that have a probability of being used by managers, decisionand policy-makers. Through another MASMA-funded project, "Developing a model for strategic adaptive management of MPAs in the Western Indian Ocean", project members working with the staff and stakeholders of the Mombasa Marine Park and using their research results as the basis assisted the Park to set new management objectives with measurable targets. They have also used their research results to evaluate progress and determine necessary management actions, and evaluated effectiveness of actions (O'Leary and Tuda 2015).

The main barriers between scientific and policy-making/management communities in the region include:

- A paucity of relevant and timely research, coupled with a willingness and concomitant capacity of decisionmakers to use it are important factors. An inadequate knowledge-base and the lack of an evidence-based management culture, technical capacity and funding are also important barriers ensuing from this.

- Several countries lack mechanisms and institutions to promote science-based management and decision-making. Such mechanisms and institutions are developing, often as part of the growing implementation of ICZM, or they may be project-based. Examples include working groups, forums and roundtables, where decision-makers and key stakeholders are engaged collectively. However, many of these mechanisms or institutions are short-lived if not supported by long-term commitment by stakeholders, or government institutions, and backed up by sufficient resources.

- Overall levels of funding for research and knowledge generation remain inadequate. This may be related to a continued lack of recognition of the socio-economic significance of marine and coastal issues in national systems of science and innovation, including research councils or their equivalent.

- Research in the countries in the WIO region for long periods has been dependent on donor funding. Donor funding, while valuable, does not promote an overall national research portfolio geared towards addressing national research priorities. Accordingly, whilst providing critical support and often strong catalytic inputs, donorfunded research contributions often do not fill research gaps since they are driven by donor priorities rather than specific national goals and needs.

- Local management authorities face many capacity challenges, which result from inadequate funding, a lack of suitably skilled staff, management tools and technical knowledge. The use of science and its products are particularly weak under these conditions.

- Many researchers and scientists do not understand nor engage with policy-making processes, which contribute to a disconnection between the scientific and policymaking communities. Scientists often conceive the link between science and policy as a one-way flow of information in which scientists convey scientific 'truth' to drive the 
development of policy. Scientist often fail to appreciate the fact that research products, no matter how well-developed and tested, can often not be incorporated directly into decision-making without the inclusion of political, economic or social realities. Similarly, the outputs provided by scientists are often in a form that is not readily assimilated by decision-makers.

- Conversely, policy-makers expect science to provide definite answers and a full cost-benefit analysis of the implications of decisions. They also often assume that scientists fully understand and describe complex problems. These may be outdated ways of thinking about science and policy but they remain common.

- A greater emphasis on co-design of trans-disciplinary projects by stakeholder including scientists, managers and civil society, and the growing importance of the contribution of all stakeholders to the scientific process (co-production of knowledge) is not fully realised or practised in the region.

\section{RESEARCH PRIORITIES AND CAPACITY NEEDS}

The Africa Progress Panel recently proclaimed that "the time has come to unleash Africa's green and blue revolutions", and, also that "Africa's farmers and fishers are equal to the challenge, but they need the opportunity. They need their governments to demonstrate more ambition on their behalf. African governments must now scale up the appropriate infrastructure and ensure that financial systems are accessible for all" (APP 2014). This State of the Coast Report has argued throughout that access to, and the use of defensible scientific data, information and knowledge is integral to management options, decisions, and policies, that the region requires to attain sustainability, as defined in the Scenario chapter (no. 32). Research funding in the region is scarce and should be optimised to achieve the most effective and longest-term outcomes possible. Regional coordination of research agendas could manage the necessary overlap of research activities in trans-boundary areas. Common priorities and coordinated research efforts could also attract funding from outside the region, especially where synergistic partnerships can be developed and coinvestment can be leveraged. The sections below briefly consider some current global and regional research priorities. In most cases, these are embraced in reports or programmes that identify priority themes which are then translated into action.

\section{Global and regional research priorities}

On a global scale, the Global Biodiversity Outlook (CBD 2014) reported on progress in meeting the Aichi Biodiversity Targets; achieving the 2050 Vision on 'Living in Harmony with Nature'; and on the importance of biodiversity in meeting broader goals for sustainable human development during this century. The Outlook identified a number of strategic goals aimed to achieve the objectives stated above. Most of the goals can be further refined for the global coastal and marine environment. The strategic goals were to:

- Address the underlying causes of biodiversity loss by mainstreaming biodiversity issues in governance processes; Reduce the direct pressures on biodiversity and promote sustainable use;

- Improve the protection of biodiversity by safeguarding ecosystems, species and genetic diversity;

- Enhance the benefits of biodiversity and ecosystem services to all; and

- Enhance implementation of biodiversity protection through participatory planning, knowledge management and capacity-building.

Similarly, the WWF published a Living Planet Report (WWF International 2014) which identified priorities to achieve sustainable use of the planet's resources. These priorities were:

- Equitable Resource Governance - Share the available resources, make fair and ecologically informed choices, measure success beyond GDP.

- Redirect Financial Flows - Value nature, account for environmental and social costs, support and reward conservation, sustainable resource management and innovation.

- Consume More Wisely - Through low-footprint lifestyles, sustainable energy use and healthier food consumption patterns.

- Produce Better - Reduce inputs and waste, manage resources sustainably, scale-up renewable energy production.

- Preserve Natural Capital - Restore damaged ecosystems, halt the loss of priority habitats, and significantly expand protected areas.

When placed in the context of global climate change, the Programme of Research on Climate Change Vulnerability, Impacts and Adaptation (PROVIA) has proposed a number of specific objectives towards our future on the changing planet. PROVIA is a global scientific initiative of the UNEP, the UNESCO and the WMO that seeks to har- 
monise, mobilise and communicate the growing knowledge base on vulnerability, impacts and adaptation (UNEP 2013). A PROVIA report (UNEP 2013) emphasises the understanding of climate change vulnerability through mapping and measurement; development and strengthening of indicator and monitoring systems; an understanding of the risks of extreme climate events, non-linear impacts and tipping points. It also promotes:

- Advancing vulnerability reduction and adaptation solutions;

- Developing more inclusive cost estimates and prioritization criteria; and,

- Enhancing communication and stakeholder/public participation.

PROVIA has also identified key systems that need attention namely: food, water, ecosystems, energy, infrastructure and the built environment. Some of the emerging topics identified by the report include impacts of geo-engineering; legal principles and the role of law; foodwater-energy-security; participatory processes for climate change mitigation and adaptation scenarios; decision theory; risk perception, climate knowledge and behaviour; governance, collaborative frameworks and networks; and long-term planning and design.

\section{Coastal and marine research priorities}

In recognition of threats to global sustainability of human activities in the ocean and coastal environment, IOC/ UNESCO, IMO, FAO, UNDP (2011) has identified the following problems as being the priority concerns:

- Unsustainable fishing;

- Climate change and ocean acidification;

- Pollution and waste; and

- Loss of habitats and biodiversity, in some cases because of invasive species.

Many international programmes have either been developed on climate change and variability, social needs and ecosystems, or have recently changed emphasis to focus on these issues. Examples include the International Geosphere-Biosphere Programme (IGBP), Intergovernmental Platform for Biodiversity and Ecosystem Services (IPBES), Scientific Committee on Oceanic Research (SCOR), Global Ocean Observing System (GOOS) together with its regional alliances, DIVERSITAS, the International Human Dimensions Programme (IHDP), the World Climate Research Programme (WCRP), Science Partnership for the Assessment of Complex Earth System
Processes (SPACES), Ecosystem Services and Poverty Alleviation (ESPA), Global Ocean Ecosystem Dynamics (GLOBEC) and the Global Change, Biodiversity, Ecosystems and Society in Africa (GCBESA) programme.

A recent WWF International report on the development of the Ocean Economy (Hoegh-Guldberg and others, 2015 ) is of direct interest to the coastal and marine environment. In this, it is contended that assets that rely on a healthy ocean environment generate more than two thirds of the annual base economic value of the ocean. As a result of a decline in the state of these assets, the associated economic activities are faltering and not delivering to their full potential. There is, however, a growing need for food and resources from the ocean. The report identified eight actions to secure our ocean assets and restore the ocean economy:

- Ensure that ocean recovery features strongly in the UN Post-2015 Agenda, including the Sustainable Development Goals;

- Take global action to avoid dangerous climate change and further damage to the ocean;

- Conserve and effectively manage 10 per cent of representative coastal and marine areas by 2020 , increasing coverage to 30 per cent by 2030 ;

- Rebuild fish stocks to ecologically sustainable harvest levels;

- Drive new global cooperation and investment in the ocean;

- Reinvent public/private partnerships;

- Build transparent accounting of the value of ocean assets to improve decision-making; and

- Share knowledge more effectively and drive institutional collaboration.

Finally, the UNEP Coastal and Marine Strategy (2011) provided some clear directives on coastal and marine actions (UNEP 2011) relevant to the need for scientific products in support of management, decision- and policymaking:

- Land-Ocean Connections: to integrate the management of coastal watersheds, the coastal area (including cities) and the marine environment to optimise the ecosystem services and resilience of marine and coastal systems. Meeting this objective will address the issue of degraded water quality in coastal water due to land-based activities.

- Ecosystems for Human Well-being: to identify, assess and value the status and key drivers of change in marine and coastal ecosystems, their services and their link to 
human well-being. The need for a better understanding of ecosystem services and their value will be addressed to meet this objective.

- Reconciling Use and Conservation: to ensure that appropriate governance frameworks, management tools, capacity and options are available for regions, countries, communities and the private sector, to effectively engage in the sustainable management of marine and coastal ecosystems, including reconciling competing uses.

- Vulnerable People and Places: to strengthen the ecological, economic and social security of vulnerable communities and places, including SIDS, to adapt and respond to natural disasters and climate change, by enhancing the resilience of marine and coastal ecosystems and social capital, and improving access and benefit sharing. Meeting this objective will help to address issues specific to SIDS, coral reefs, seamounts and other sensitive marine ecosystems.

\section{DEVELOPMENT OF CAPACITY FOR RESEARCH}

The National Research Council (NRG) of the National Academy of Science (NAS) (NRG-NAS 2008) describes capacity building as "programs designed to strengthen the knowledge, abilities, relationships and values that enable organizations, groups and individuals to reach their goals for sustainable use of ocean and coastal resources. It includes strengthening the institutions, processes, systems and rules that influence collective and individual behaviour and performance in all related endeavours. Capacity building also enhances people's ability to make informed choices and fosters their willingness to play new developmental roles and adapt to new challenge." This holistic definition of the capacity building encompasses much more than training but also includes different levels (individual, institutional, enabling environment) and all phases of the knowledge generation and knowledge translation cycle (from setting the research agenda and research design to research use and communication). This is an important distinction as it reflects the reality of variable capacities across countries and regions, and also recognises that there are strong needs at all phases from research data collection through to the assimilation and mainstreaming of the knowledge gained into decision-making.

Though most of the countries in the region achieved independence between the early 1960s and mid-1970s, it was not until the 1970 that a noticeable increase in the number of marine scientists occurred. During this period the first marine scientists were completing their postgradu- ate studies. They were initially few in number and mainly fisheries biologists by specialisation. During the 1980s and 2000s, more marine scientists from a spectrum of disciplines (both in natural and social science) were trained.

\section{Capacity-building needs in resource management authorities}

Different types of management authorities, from national ministries responsible for policy development to local governments and protected area management structures, are responsible for policy implementation and day-to-day management of coastal and marine resource use. These are vastly different in character and, as a result, have different capacity-building requirements.

Institutions responsible for development of policies, programmes and strategies at the national level include both politically-appointed officials as well as technical staff. The extent to which politically-appointed officials have adequate technical competence for marine and coastal management varies. However, these institutions also have technical personnel that are often highly qualified, in many cases in areas directly relevant to coastal and marine management, and with a good understanding of science. On the whole, at the national level in some countries, there is often requisite capacity (if not always the political will) to source and apply science to policies, legislation, plans and strategies.

At this level, and in view of the findings presented in previous sections of this chapter, some relevant capacitybuilding interventions are needed, aimed at management authorities. These include:

- Reinforcing the capacity of decision-makers to formulate policy and associated research needs through forward-looking methodologies such as envisioning future scenarios. These involve considering how emerging trends and developments might affect policy and practice. Policy-makers need to understand current and future drivers of change and plan accordingly, identifying and prioritizing research issues that will address emerging challenges.

- Enhancing mutual understanding of how scientific and management communities operate through specific training to address some prevailing misconceptions. Another way to enhance mutual understanding would be to promote secondment of managers to research institutions and scientists to management authorities for "job-shadowing". 


\section{Capacity-building strategies to overcome barriers to effective integration of science}

Overcoming the barriers to effective integration of science into decision-making and management processes cannot be achieved through capacity building alone. There are, however, a number of additional strategies that would strengthen the link between science and marine and coastal management. These include:

- Support for knowledge brokerage in boundary organisations. These could identify, review and synthesise all available scientific information relevant for a particular policy or management issue and effectively interact with decision-makers.

- Compile project-level lessons-learned that link science and policy and management, highlighting successes.

- Support projects that combine research and demonstration or implementation activities. There are successful cases in the WIO that will yield useful lessons such as the Rodrigues octopus fisheries project (Yvergniaux, undated) and the MASMA-funded project "Developing a model for strategic adaptive management of MPAs in the Western Indian Ocean” (O’Leary and Tuda 2015).

\section{Regional capacity-building initiatives}

Capacity-building initiatives have taken different forms in the region, including capacity building of individuals, institutions and society in general. Such efforts have aimed at improving their understanding of processes in, and the value of, coastal and marine environments. Capacity-building initiatives have also targeted institutions to improve their decision-making processes and build their technical skills to better fulfil their mandates. Some capacity-building initiatives have also targeted civil society with the aim of building their capacity to empower people to understand, engage in, and resolve issues associated with the better use and management of resources to maximize their opportunities for livelihood improvement.

In this context, several mechanisms have been used to deliver these different forms of capacity-building, including:

- Technical short-term courses. These types of courses have covered different types of specialised technical subjects that often represent enabling knowledge or skill sets such as nutrient analysis, coral reef monitoring, algal physiology, coastal erosion and leadership. The Nairobi Convention, in collaboration with the IOC-UNESCO and WIOMSA, organized a number of leadership courses targeting senior scientists and heads of research and academic institutions. Such short-term courses have been instrumental in laying the foundation for collaboration between national and regional institutions. They have promoted of the use of the same or comparable techniques in fieldwork and laboratory studies, as well as raised awareness and information dissemination and promoted leadership for marine related research and management at the highest levels of governance.

- Writing workshops. WIOMSA, through its MASMA Programme, has been providing grants for writing workshops. Specifically, these workshops seek to assist participants to attain a level of scientific and grant writing that can compete on a global scale for grants and publications. In these workshops, participants are asked to bring their own data with the aim of synthesizing information from multidisciplinary projects as well as information from relevant projects supported by other partners, leading to publications in peer-reviewed journals or books or policy briefs. Writing workshops have become a common feature of most of the MASMA-funded projects. They have provided opportunities to brainstorm on key research results, as well as for capacity building amongst emerging scientists in terms of approaches to data analysis, information synthesis and access, and the best methods for the dissemination of information and results.

- Practitioner Short Courses. These include broadbased training on marine protected area or natural resource management and ICZM that combine learning in a workshop setting with field visits and opportunities for the exchange of experience. Courses of this kind aim to address the need to rapidly develop a general understanding of emerging issues where there is limited capacity. Introduction level and general courses are then superseded by more specialised technical courses and/or integration into vocational and masters training courses.

- Multi-Stage Courses. Multi-stage courses combine on-the-job-learning and assignments with one or more intensive training sessions, often involving exposure to projects or other real-life management situations that provide the experience participants need to build their own capabilities. Participants then complete assignments and projects based on their workplace (or volunteer) experience (Coley and others, 2002).

- Certification of professionals. WIOMSA recognised the importance of the marine conservation and compliance sector when it instituted WIO-COMPAS (Box 


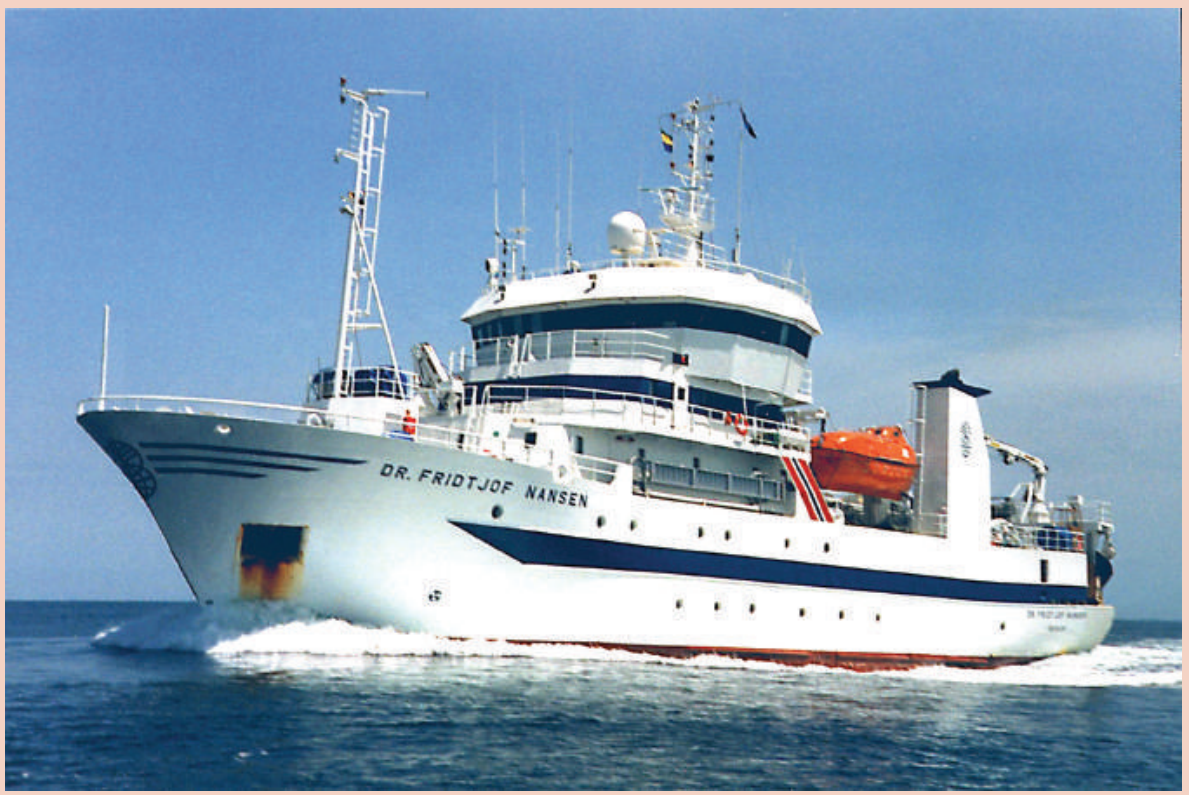

R/V Dr. Fridtjof Nansen, one of the vessels used during the ASCLME-coordinated cruises. () EAF-Nansen project.

This Project ran from 2007 until 2014 and supported nine countries in the western Indian Ocean region to undertake an environmental baseline assessment of the Agulhas and Somali Current Large Marine Ecosystems, to fill the information gaps needed to develop a Transboundary Diagnostic Analysis (TDA) and to support improved management decision-making through development and adoption of a Strategic Action Programme (SAP).

The main achievements from the Project included the development of National MEDAs (Marine Ecosystem Diagnostic Analyses) as 'state of the marine environment' reports for each country; integration of the MEDAs into a single, regional Transboundary Diagnostic Analysis; a draft Strategic Action Programme for Management of the LMEs; and a Western Indian Ocean Sustainable Ecosystem Alliance of partners that agreed to support scientific research, monitoring, capacity building and training.

More specifically in the context of actual scientific research as well as capacity building and training, the project has listed the following deliveries and successes in collaboration with its many partners:

\section{Scientific Studies and Research}

- 50 individual cruises 'legs' around the western Indian Ocean
- Deployment of permanent ocean-atmosphere monitoring mooring systems

- Use of satellite imagery to track productivity hotspots and identify upwelling incidents

- Study of ocean kinetics, particularly in relation to eddies associated with the Mozambique channel

- Substantial data collected on primary and secondary productivity as well as fish biodiversity and genetics (including comprehensive fish collections)

- Fisheries data reconstructions to demonstrate significance of small-scale fisheries

- Studies on marine-based pollutants and extent of landbased pollution impacts offshore

- Mapping of invasive species distributions

- Mapping of critical habitats and vulnerable/endangered species along with proposed management measures

- National and regional policy and governance baseline assessments completed with recommendations for strengthening and harmonising across the region

- Regional 'Cost-Benefit of the Ecosystem Approach' assessment completed

Individual national demonstration on community engagement and evolution of local economic development plans)

\section{Capacity Building and Training}

- Nearshore and coastal monitoring programmes developed 
and agreed with each country in support of the ecosystembased management approach

- Training of more than 100 new scientists on ecosystem monitoring and assessment techniques

- A 3-week intensive study and filed-work course providing a grounding in theoretical oceanography follow by 'hands-on' training at sea in data collection, analysis and survey planning

- Co-development and co-delivery (with the International Ocean Institute and University of Cape Town) of a 4-week Ocean
Governance Training Course for managers

- Numerous workshops on such topics as the use of GIS and remote sensing; marine pollution; invasive species, port control, taxonomy, etc.

- A regional Capacity Building and Training Needs road-map developed for the countries Cooperative agreements with various 'Alliance' partners for long-term delivery of CB\&T needs repatriation of data, where possible from previous scientific activities.
35.2), the Western Indian Ocean Certification of Marine Protected Area Professionals (WIO-COMPAS 2012). This is a joint initiative of WIOMSA and the Coastal Resources Center (CRC) at the University of Rhode Island (URI). The initiative was further refined in liaison with leading conservation professionals in a number of African countries. Entrants to the programme are assessed by leading professionals and are certified at three levels: Level 1 Marine Field Operations; Level 2 - Site Management; and Level 3 - Policy and Planning. All of these levels of certification are of relevance to the management situation under consideration and the WIO-COMPAS initiative thus merits support as it offers redress to what appears to be the most burning gap in the capacity-building needs of the region.

- Tertiary education leading to BSc, MSc and Phds has been accomplished by course work (for BSc) and via other mechanisms such as training abroad through scholarships programmes offered by various international organizations such as Sida, CIDA, NORAD, AusAid, Commonwealth, GTZ, Belgium and JICA, and 'sandwich' programmes, whereby students spend the majority of their time in their home countries working on a locally relevant research problem. There are two modes of training under such arrangements. In the first, candidates are registered at overseas universities and attend courses, undertake data analysis and thesis write-up at that university, while in the second mode, the candidate is registered at a regional university and part of the data analysis and thesis write-up takes place at an overseas university.

- Increasing accessibility of research results through organisation of the conferences and scientific symposia.

- The development of training materials and guides such as the WIO MPA Toolkit (IUCN 2004). This type of initiative aims to produce appropriately designed and rel- evant technical information, methodologies, guidelines and training to underpin best practise in one or more natural resource management areas.

\section{CONCLUSION}

The WIO region has, over the years, built capacity for coastal and marine research and it is reasonable to state that increasing the pool of coastal and marine data, information and knowledge (scientific evidence) has resulted in an improvement of management of the coastal and marine environments. As indicated earlier, scientific research commissioned within the context of national growth and development is more likely to directly impact on resource management and the development of policy compared to research solely driven by external support. Where there is a clear expression of need for data, information and knowledge by managers and policy-makers in context of a national, regional or sub-national vision, the research is much more likely to be applied to solve real-world problems that then directly improve the situation locally, nationally, and, regionally. This does not, however, reduce the relevance of the global coastal and marine research agenda as expressed by the United Nations agencies and international NGOs such as WWF for the WIO, and these agendas can contribute to the basis for developing regional research priorities.

Most of the experiences of scientists and managers in the WIO region indicate a persistent perception that science to policy is predominantly a one-way affair, from producer to user. Whilst there is clearly a much stronger role for policy-makers and their advisers in developing research questions and agendas, it is also true that managers and decision-makers often do not understand the limits of scientific data, and their inherent risks and the issues of tem- 
poral and spatial applicability. Concomitantly, in a space as complex as the coastal and marine environment, scientific data is not the only informant of decision-making and this perspective warrants development among researchers and research organisations alike. The task of connecting or coproducing scientific knowledge with users is not an automatic process and there needs to be a concerted effort to own the problem of producing usable science in the WIO.

The WIO encompasses a wealth of research and management institutions and agencies and yet, the overall human capacity in the region is still not consummate to the needs of addressing the complex and multidisciplinary issues in the coastal and marine environments it is comprised of. This is a result of amongst others, inade- quate financial and human resources resulting from the low percentage funding for R\&D in relation to GDPs of most countries, and insufficient investment in education and training, inadequate knowledge and awareness arising from factors such as lack of or inadequate regulations, and a lack of legal expertise. Generally speaking, the interactions between science, policy and management in the WIO take place in a context of limited, and often inadequate human capacity, including inadequate governance capacity, research capacity and capacity for fulfilling financial, operational and human resource functions. Investment and innovative approaches to building human capacity development remains a top priority for countries in the WIO.
BOX 35.2. WESTERN INDIAN OCEAN CERTIFICATION OF MARINE PROTECTED AREAS PROFESSIONALS (WIO-COMPAS) by Michael H. Schleyer

\section{WIO C-MPAS \\ Western Indian Ocean - Certification of Marine Protected Area Professionals}

The overall goal of WIO-COMPAS is to establish a professional association that provides a framework to promote competence, professionalism, leadership, innovation and ethical conduct amongst Marine Protected Area (MPA) managers. It recognizes and accredits individuals working in MPAs whose knowledge and skills meet a clearly defined professional standard. It then further enhances their knowledge and skills through networking with other professionals, sharing new ideas and thinking about MPA management and coastal governance.

The WIO-COMPAS programme is structured around the four elements of Experience, Examination, Education and Ethics. While it does not provide training, it does provide candidates professional development sessions during the certification assessment. Applicants are selected on merit and undergo a rigorous assessment during which they are

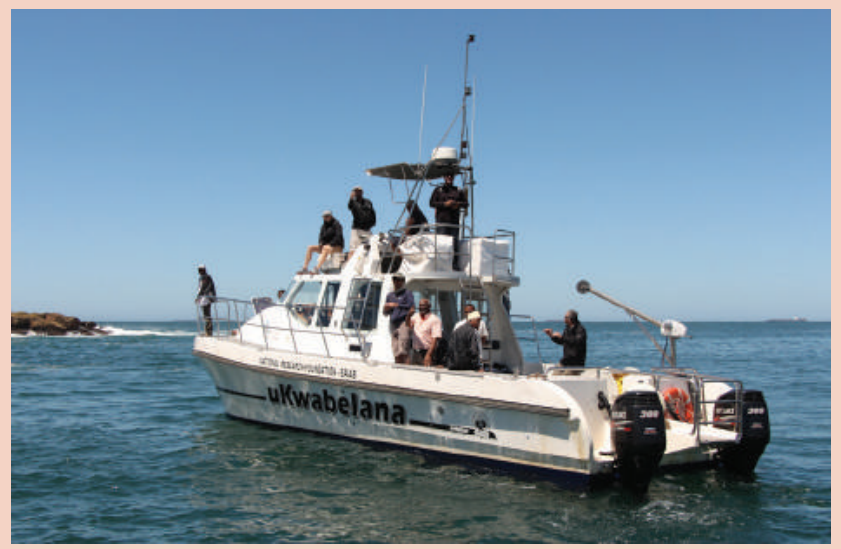

Participants of the Western Indian Ocean Training on Understanding and Communication Climate Change on a field trip in Algoa Bay, South Africa. ๑ Yoon Kim.

scored in their competence in multiple areas. A code of ethics binds together individuals who become certified - known as MPA PROs - to uphold the high standards of the programme and their profession. A total of 68 MPA PROs have been accredited since the launch of WIO-COMPAS in 2012.

Source: Coastal Resources Center and WIOMSA (2012)

\section{References}

References - Chapter 35 - Coastal and marine research and APP (2014). Grain, Fish, Money - Financing Africa's Green and capacity building

Blue Revolutions. Africa Progress Panel. Africa Progress 
Report 2014

CBD (2014). Global Biodiversity Outlook 4. A mid-term assessment of progress towards the implementation of the Strategic Plan for Biodiversity 2011-2020. Secretariat of the Convention on Biological Diversity. Montréal

Coley, C., Squillante, L., Hale, L., Kiambo, R., Francis, J. and Mbarouk, F. (2002). Learning and Performing: developing Skills for Coastal Management Practitioners. Final Report on the First Course on building Capacity for Sustainable Integrated Coastal Management in the Western Indian Ocean Region. WIOMSA/CRC

COSTECH (undated). Tanzania Commission for Science and Technology. Available at http://www.costech.or.tz/

Davis, C. and Carden, F. (1998). Research effectiveness and $\mathrm{R}$ and $\mathrm{D}$ evaluation in developing countries. Knowledge and Policy 10(4), 7-30

EAMFRO (1965). Annual Report. East African Marine Fisheries Research Organization. East African Common Services Organization

Hoegh-Guldberg, O. (Lead Author) (2015). Reviving the Ocean Economy: the case for action - 2015. WWF International. Gland, Switzerland, Geneva

HRDC (2006). Transforming Mauritius into a Knowledge Hub. Human Resources Development Council. Ministry of Education and Human Resources Sectoral Committee Report

IOC/UNESCO, IMO, FAO, UNDP (2011). A Blueprint for Ocean and Coastal Sustainability. An inter-agency paper towards the preparation of the UN Conference on Sustainable Development (Rio+20). IOC/UNESCO. Paris, France

IUGN (2004). Managing Marine Protected Areas: A Toolkit for the Western Indian Ocean. IUCN Eastern African Regional Programme. Nairobi, Kenya, 172 pp. http:// www.wiomsa.org/mpatoolkit/

Morcos, S. (2002). The Education Mission of Marine Sciences: A case study of East Africa, the early initiatives, 1930-1980. In Oceanography History: The Pacific and Beyond (eds. K.R. Benson and P.F. Rehbock) pp. 215223. University of Washington Press

NACOSTI (undated). National Commission for Science, Technology and Innovation. Available at http://www.ncst. go.ke/

NRC-NAS (2008). Increasing Capacity for Stewardship of Oceans and Coasts: A Priority for the $21^{\text {st }}$ Century. Committee on International Capacity Building for the Protec- tion and Sustainable Use of Oceans and Coasts of the Ocean Studies Board. National Research Council of the National Academies of Science. National Academies Press, Washington, D.C.

O'Leary, J. and Tuda, A. (2015). Using Science to Empower Communities and Improve Marine Protected Areas in East Africa. Available at http://voices.nationalgeographic. com/2015/02/24/using-science-to-empower-communities-and-improve-marine-protected-areas-in-eastafrica/

Rao, T.S.S. and Griffiths, R.C. (1998). Understanding Indian Ocean: Perspective on Oceanography. UNESCO. Paris, France

Richmond, M.D. (ed.) (2011). A field guide to the seashores of Eastern Africa and Western Indian Ocean Islands. Sida/ WIOMSA

Robinson, J., Marguerite, M., Payet, R. and Isidore, M. (2007). Investigation of the Importance of the Reef Fish Spawning Aggregations for Sustainable Management of Artisanal Fisheries Resources in Seychelles. MASMA Final Technical Report. WIOMSA Book Series No 6

RoK (2008). Science, Technology and Innovation Policy and Strategy. Republic of Kenya. Ministry Of Science and Technology. Nairobi, Republic of Kenya

RoMZ (2006). Estratégia de Ciência, Tecnologia e Inovação de Moçambique (ECTIM). Republic of Mozambique, Conselho de Ministros.

RSA (2002). South Africa's National Research and Development Strategy. Republic of South Africa.Department of Science and Technology, Government of the Republic of South Africa, Pretoria

The World Bank (undated). Research and development expenditure (\% of GDP). Available at http://data.worldbank.org/indicator/GB.XPD.RSDV.GD.ZS

UDC (2013). Politique Nationale de l'Enseignement Superieur et de la Recherche a l'Horizon 2020, Mars 2013. Union de Comores. Ministère de L'education Nationale de la Recherche de la Culture et des Arts Charge de la Jeunesse et des Sports. 25 pp

UIS (2010). MEASURING R\&D: Challenges Faced by Developing Countries. UNESCO Institute for Statistics. Quebec, Canada. 40pp. www.uis.unesco.org/template/pdf/S\&T/TechPaper5_EN.pdf

UNEP (2011). Marine and Coastal Strategy: The Other 70\% Executive Summary. UNEP. Kenya

UNEP (2013). Research Priorities on Vulnerability, Impacts and Adaptation - Responding To The Climate Change Chal- 
lenge: Priorities on Impacts and Adaptation to the Climate Change Challenge. United Nations Environment Programme. Nairobi

URT (2010). The National Research and Development Policy. United Republic of Tanzania. Ministry of Communication, Science and Technology. United Republic of Tanzania

WIO-COMPAS (2012). Western Indian Ocean - Certification of Marine Protected Areas Professionals Program Handbook: Overview, Processes, Competences and Rules. Coastal Resources Center and WIOMSA

WWF International (2014). Living Planet Report 2014 - Species and spaces, people and places. WWF International. Switzerland, Geneva

Yvergniaux, Y. (undated). Management of the octopus fishery in Rodrigues. Smart Fiche 12, SMARTFISH Programme 


\section{Part VIII \\ Overall Assessment}


L EinaIBESOCBindd 486 


\section{Overall Assessment of the State of the Coast in the Western Indian Ocean}

- INTRODUCTION

- The WIO region main features

- The mandate and methodology of the RSOCR for the WIO

- $\quad$ ASSESSMENT OF BIODIVERSITY

- Drivers of change

- Pressures on marine ecosystems and species

- State and trends of the marine environment

- Impacts on the marine environment and related livelihoods

- Society responses

- General recommendations regarding biodiversity

- ASSESSMENT OF SERVICES FROM THE MARINE ENVIRONMENT OTHER THAN PROVISIONING

- Climate regulation in the WIO

- Support to primary production by the WIO

- Support to ocean-sourced carbonate production by the WIO

- Cultural services of the WIO

- General recommendations regarding ecosystem services other then provisioning

- ASSESSMENT OF FOOD SECURITY FROM MARINE RESOURCES

- Capture fisheries

- Mariculture

- General recommendations regarding food security from marine resources

- Coastal development and vulnerability

Catchments

- Genetic resources and bio-prospecting

- General recommendations regarding other human activities

- Future scenarios for the WIO region 520

- $\quad$ The CWS scenario 521

- $\quad$ The SWS scenario

- $\quad$ The way forward

Research and capacity-building 
